\title{
Učinkovitost sustava za navodnjavanje kukuruza (Zea mays L.) ovisno o različitim vremenskim uvjetima, normi navodnjavanja i $\mathbf{N}$ gnojidbi
}

\section{Sažetak}

U radu su prikazani rezultati trogodišnjeg (2010. - 2012.) poljskog pokusa u kojem je istraživan utjecaj godine ( $a 1=2010 . ; a 2=2011$.; $a 3=2012$.), učinkovitost normi navodnjavanja (b1 = kontrola; $b 2=60$ do $80 \%$ poljskog vodnog kapaciteta (PVK), b3 = 80 do 100\% PVK), količine N gnojiva (c1 = kontrola; $c 2=100 \mathrm{~kg} \mathrm{Nha}{ }^{-1}$; $c 3=200 \mathrm{~kg} \mathrm{~N} \mathrm{ha}^{-1}$ ) te njihova interakcija na prinos i komponente prinosa kukuruza: duljina klipa (DK), visina klipa (VK), masa zrna po klipu (MZ/K) te broj zrna po klipu (BZ/K) i njihova korelacijsku povezanost. Utjecaj godine na prinos zrna kukuruza u pokusu nije bio izrazit $\left(a 1: 8,6\right.$ t ha $^{-1}$, a2: 8, 4 t ha ${ }^{-1}$ i 8, 3 tha $\left.{ }^{-1}\right)$, jer je navodnjavanje vrlo značajno utjecalo na prinos zrna kukuruza posebice u ekstremno vrlo sušnoj $i$ ekstremno toploj 2012. godini (a3b1: 6,7 tha ${ }^{-1}$, a3b2: 8,2 tha $a^{-1}$ i a3b3: 9,9 tha $\left.{ }^{-1}\right)$. Vrlo značajno $(P<0,01)$ godina je utjecala na VK s rasponom od 97,4 (a1) do 133,5 cm (a2), DK od 18,6 (a1) do 21,4 cm (a3) i BZ/K od 566 (a1) do 628 (a3). Povećanjem norme navodnjavanja (od b1 do b3) vrlo je značajno povećan prinos zrna od 7,5 do $9 \mathrm{t} \mathrm{ha}^{-1}$, VKod 115,1 do 125,8 cm i značajno $(P<0,05)$ je povećan $B Z / K$ od 536 do 612 . Povećanjem količine N gnojiva (od c1 do c3) vrlo značajno je povećan prinos zrna 6,5 do 10,3 tha ${ }^{-1}$, DK od 18,4 do $20,9 \mathrm{~cm}, \mathrm{BZ} / \mathrm{K}$ 536 do 651 i VK od 113,5 do 124,8 cm. Rezultati istraživanja variraju u odnosu na godinu jer su vegetacijska razdoblja obilježili ekstremni vremenski uvjeti, od prekomjerne količine oborine 2010. godine do pojave sušnih razdoblja 2011. i 2012. godine praćenih nadprosječno visokim temperaturama zraka. Značajnost interakcija razlikovale su se po godini istraživanja. Jaka pozitivna korelacija je između prinosa zrna i DK $(0,55)$ te prinosa zrna i $B Z / K(0,62)$.

Ključne riječi: godina, navodnjavanje, N gnojidba, kukuruz, prinos, komponente prinosa

\section{Uvod}

Kukuruz (Zea mays L.) je jedna od najzastupljenijih žitarica na proizvodnim površinama Republike Hrvatske. U posljednjih sedamnaest godina (2000. - 2016.) kukuruz je uzgajan na prosječno 283.387 ha uz prosječan prinos $6,4 \mathrm{t} \mathrm{ha}^{-1}$ (DZS, 2016.). U spomenutome razdoblju prinosi kukuruza bili su u rasponu od 4,1 t ha-1 (2000.) do 8,5 $\mathrm{t} \mathrm{ha}^{-1}$ (2016.). Ispodprosječni prinosi rezultat su nepovoljnih vremenskih uvjeta, prvenstveno nedovoljne i nepravilno raspoređene oborine tijekom razdoblja vegetacije jarih kultura. Na području istočne Hrvatske (Osječko-baranjske županije) sušna razdoblja sve su učestalija, a kao rezultat javlja se negativna vodna bilanca koja za posljedicu ima pad prinosa. Jedno od mogućih rješenja ublažavanja negativnih posljedica suše je nadoknađivanje vode navodnjavanjem. Učinak vodnoga stresa izazvan sušom na prinos zrna kukuruza proučavali su Kuscu i Demir (2013), Gavloski i sur. (1992.), Golbashy i sur. (2010.), Jaleel $i$ sur. (2002.), Payero i sur. (2006.), Traore $i$ sur. (2000.). Autori navode niže prinose zrna te ukazuju na povezanost između prinosa i komponenti prinosa kao što su duljina klipa, broj zrna na klipu i mase zrna. Hammad i sur. (2012.) proučavali su učinak vodnoga stresa na prinos zrna, broj zrna na klipu, masu

Doc. dr. sc. Monika Marković, Sveučilište J. J. Strossmayera u Osijeku, Poljoprivredni fakultet u Osijeku, Zavod za bilinogojstvo, Vladimira Preloga 1, 31000 0sijek, e-mail: monika.markovic@pfos.hr

Prof. dr. sc. Jasna Šoštarić, Sveučilište J. J. Strossmayera u Osijeku, Poljoprivredni fakultet u Osijeku, Zavod za bilinogojstvo, Vladimira Preloga 1, 31000 0sijek, e-mail: jasna.sostaric@pfos.hr

Dr. sc. Marko Josipović, Poljoprivredni institut u 0sijeku, Južno predgrađe 17, 31000 0sijek, e-mail: marko.josipovic@poljinos.hr Žejko Barač, mr. sc., Sveučilište J. J. Strossmayera u Osijeku, Poljoprivredni fakultet u Osijeku, Zavod za poljoprivrednu tehniku, Vladimira Preloga 1, 31000 0sijek, e-mail: zeljko.barac@pfos.hr 
zrna, duljinu klipa, promjer klipa i masu zrna kukuruza. $U$ rezultatima istraživanja navode značajan učinak vodnoga stresa na prinos i broj zrna na klipu te navode najznačajniju korelacijsku vezu $(r=0,85)$ između ta dva svojstva. Li i Wang (2011.) navode najznačajniju povezanost prinosa s masom klipa i masom zrna na klipu. Nadalje, nedostatak vode može imati za posljedice niže biljke (Soler i sur., 2007.), a Karasu i sur. (2015.) navode najznačajniju korelaciju između prinosa zrna i visine biljke kukuruza $\left(r=0,96^{* *}\right)$. Nedostatak biljci pristupačne vode tijekom razdoblja vegetacije nadoknađuje se normom navodnjavanja. Povećanjem norme navodnjavanja raste prinos zrna kukuruza, broj zrna na klipu (Karasu i sur., 2015.), broj zrna u redu (Carpici, 2009., Karasu i sur., 2015., Kuscu, 2010.), masa zrna, dužina klipa (Ertek i Kara, 2013., Kuscu, 2010.) i visina biljke (Karasu i sur., 2015., Bozkurt $i$ sur., 2006.). Pored vode u tlu, količina $\mathrm{N}$ gnojiva je najvažniji čimbenik za postizanje visokih i stabilnih prinosa kukuruza (Hammad i sur., 2012.). Povećanjem količine N gnojiva raste prinos zrna kukuruza i broj zrna na klipu, komponenta koja je u najjačoj korelaciji s prinosom (Devi i sur., 2001., Khaliq $i$ sur., 2009., Khazaei $i$ sur., 2010.). Khazaei $i$ sur. (2010.) u rezultatima istraživanja navode kako prinos nije značajno varirao u odnosu na količinu $\mathrm{N}$ gnojiva te da je najduži klip kukuruza izmjeren pri gnojidbi s najmanjom količinom N gnojiva 120 $\mathrm{kg} \mathrm{N} \mathrm{ha}^{-1}$. Značajan je također utjecaj interakcije navodnjavanje $x \mathrm{~N}$ gnojidba na prinos zrna (Hammad i sur., 2012.), a D'Andrea $i$ sur. (2008.) navodi i značajan utjecaj godine na prinos. Nadalje Karasu i sur., (2015.) navode značajnost interakcije godina x navodnjavanje za prinos zrna, broj zrna na klipu i visinu biljke. Cilj rada je utvrditi utjecaj godine, norme navodnjavanja, količine dodanoga $\mathrm{N}$ gnojiva na prinos i komponente prinosa kukuruza: duljinu klipa (DK), visinu klipa (VK), masu zrna po klipu (MZ/K) te broj zrna po klipu (BZ/K) i njihovu korelacijsku povezanost.

\section{Materijali i metode}

Trogodišnje (2010. - 2012.) istraživanje provedeno je na pokušalištu Poljoprivrednoga instituta Osijek. Proučavan je utjecaj godine (a1 = 2010.; a2 = 2011.; a3 = 2012.), normi navodnjavanja ( $\mathrm{b} 1=$ kontrola; $\mathrm{b} 2=60$ do $80 \%$ poljskog vodnog kapaciteta (PVK), b3 $=80$ do $100 \%$ PVK), količine N gnojiva ( $c 1=$ kontrola; $c 2=100 \mathrm{~kg} \mathrm{~N} \mathrm{ha}^{-1} ; \mathrm{c3}=200 \mathrm{~kg} \mathrm{~N} \mathrm{ha}^{-1}$ ) te njihovu interakciju na prinos i komponente prinosa kukuruza (Zea mays L.): duljinu klipa (DK), visinu klipa (VK), masu zrna po klipu (MZ/K) te broj zrna po klipu (BZ/K) i njihovu korelacijsku povezanost. Istraživanje je postavljeno prema split-plot shemi slučajnog rasporeda u tri ponavljanja (117,6 x 94 m dimenzije su jednoga ponavljanja). Na rubnom dijelu svake pokusne parcele posijana su tri reda kukuruza (zaštitni pojas) te je između parcela ostavljen prolaz širine $2 \mathrm{~m}$ kako bi se izbjeglo preklapanje tretmana navodnjavanja i N gnojidbe i omogućilo kretanje sustava za navodnjavanje. Na pokušalištu je tip tla antropogenizirani hidromeliorirani hipoglej. U sloju tla od 0 do $32 \mathrm{~cm}$ gustoća čvrste faze (pč) je od $2,6 \mathrm{~g} \mathrm{~cm}^{-3}$, volumna gustoća $1,5 \mathrm{~g} \mathrm{~cm}^{-3}$, kapacitet za vodu\%vol. od $36,6 \%$ i ukupna poroznost $41,8 \%$. Na dubini od 0 do $40 \mathrm{~cm} \mathrm{pH}$ je $7,5\left(\mathrm{H}_{2} \mathrm{O}\right)$ i $6,8(\mathrm{KCl}), 1,6 \%$ humusa te $0,13 \%$ N. Tijekom istraživanja (2010. - 2012.) kukuruz je navodnjavan metodom kišenja, samohodnim sektorskim rasprskivačem (Typhon) s prosječnom brzinom kretanja od $18 \mathrm{~cm} \mathrm{~min}{ }^{-1}$ te dometom od 22 do $25 \mathrm{~m}$. Radni tlak na izlasku vode iz rasprskivača je do 2,5 bar. Izvor vode za navodnjavanje bila je podzemna voda (obližnji zdenac). Prema analizi SAR vrijednosti (11 me/l uz ECw od 0,97 dS/l) vodom iz zdenca navodnjavati se može uz slabo do umjereno ograničenje (FAO, 1985.). Trenutak početka navodnjavanja određen je prema trenutačnoj vlažnosti tla metodom elektrometrije, Granular Matrix senzorima (GMS). 
Senzori su postavljeni na dvije dubine $(20$ i $30 \mathrm{~cm}$ ), a za trenutak početka navodnjavanja uzeti su prosjeci dvaju dubina. Sadržaj vode u tlu mjeren je Watermark uređajem čije su vrijednosti u rasponu od 0 cbar (100\% PVK) do 199 cbar (suho tlo). Prije postavljanja u tlo GM senzori baždareni su za tip tla koji je na pokušalištu te je izrađena krivulja baždarenja (Grafikon 1, Marković, 2013.).

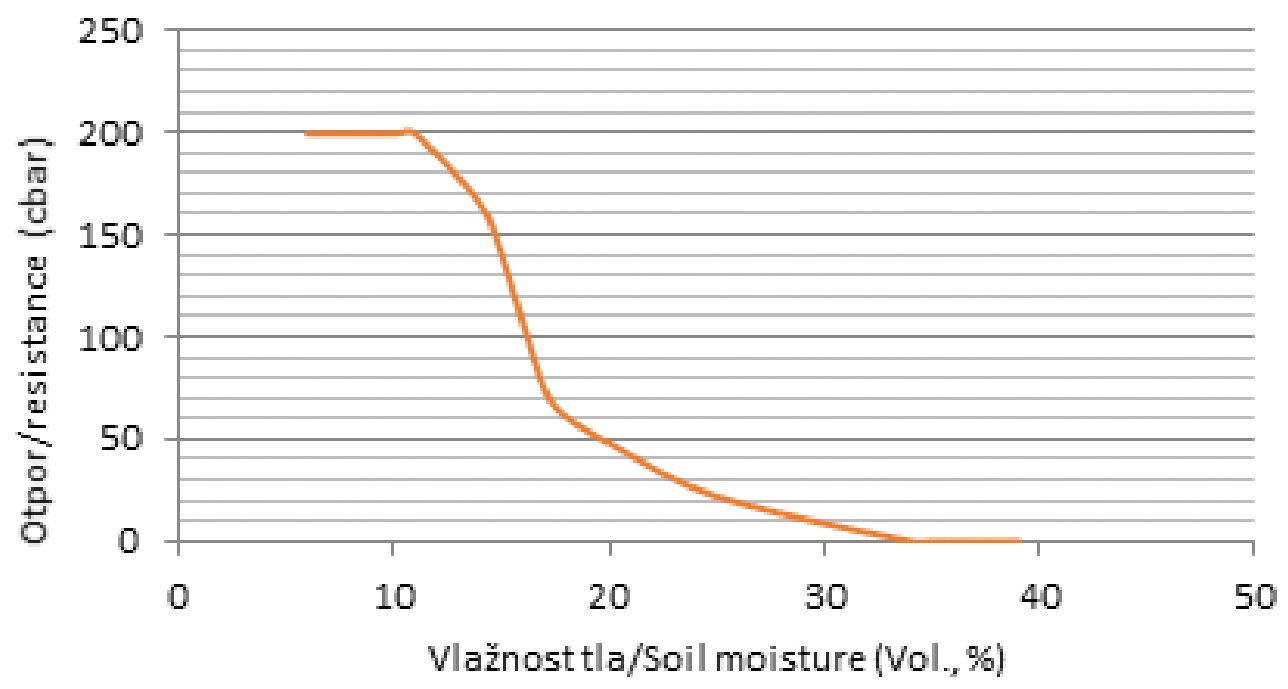

Grafikon 1. Krivulja baždarenja

Figure 1. Calibration curve

Obrok navodnjavanja tijekom trogodišnjeg istraživanja bio je $35 \mathrm{I} \mathrm{m}^{2}$ na svim navodnjavanim parcelama. Tijekom istraživanja (2010. - 2012.) osnovnom gnojidbom u jesen dodana je $1 / 3 \mathrm{~N}$ gnojiva i $1 / 2$ PK. Predsjetvena gnojidba Ureom (1/3 N) bila je 20. travnja (2010.), 18. travnja (2011.) i 12. travnja (2012.). Gnojidba PK (1/2) kako slijedi: 0:20:30 - 250 $\mathrm{kg} \mathrm{ha}^{-1}, \mathrm{P}_{2} \mathrm{O} 5(45 \%)-50 \mathrm{~kg} \mathrm{ha}^{-1}, \mathrm{~K}_{2} \mathrm{O}(60 \%)-75 \mathrm{~kg} \mathrm{ha}^{-1}$. Prva prihrana KAN-om bila je 11. lipnja (2010.), 29. lipnja (2011.) i 30. svibnja (2012.). Druga prihrana KAN-om bila je 18. lipnja (2010.), 7. lipnja (2011.) i 8. lipnja (2012.).

Prinos i komponente prinosa mjereni su na hibridu OSSK596. Kukuruz je posijan na dubinu od $10 \mathrm{~cm}$, na međuredni razmak $70 \mathrm{~cm}$ i na razmak unutar reda $20 \mathrm{~cm}$ (6. svibnja 2010., 3. svibnja 2011. i 28. travnja 2012.). Tijekom kombajniranja sa sredine svake pokusne parcele ubrano je 5 prosječnih klipova kukuruza na kojima su izmjerene komponente prinosa. Prinos zrna sa svake pokusne parcele preračunat je na ha i $14 \%$ vlage. Mjerena je razina podzemne vode u obližnjem zdencu, a podaci o vremenskim uvjetima preuzeti su od Državnog hidrometeorološkog zavoda. Provedena je trofaktorijalna analiza varijance ( $\mathrm{x} \times \mathrm{b} \times \mathrm{c}$ ) pomoću računalnog programa SAS (SAS Institute, Inc., Cary, NC, USA). Razine statističke značajnosti bile su $\mathrm{P}<0,05$ i $\mathrm{P}<0,01$. Izračunate su najmanje značajne razlike (LSD) za sve varijable $(P<0,05$ i $P<0,01)$. Pomoću korelacijskog koeficijenta ispitana je jačina i smjer veze među promatranim varijablama. 


\section{Rezultati i rasprava}

Agroekološki uvjeti tijekom razdoblja istraživanja

Odstupanje u količini oborine tijekom razdoblja istraživanja prikazano je grafikonom 2.

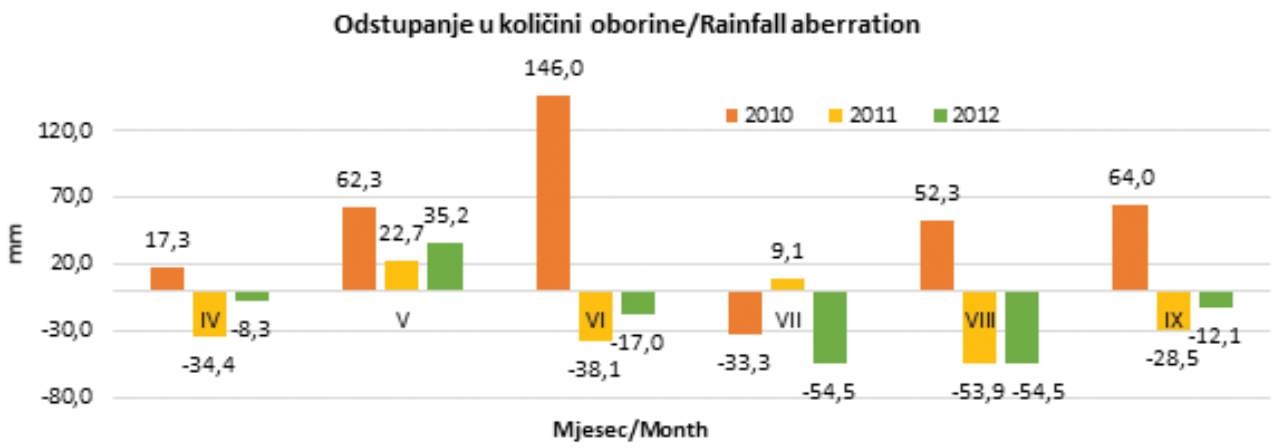

Grafikon 2. Odstupanje u količini oborine (2010. - 2012.) u odnosu na višegodišnji prosjek (1961. - 1990.)

Figure 2. Rainfall aberration (2010. - 2012.) from the long term average (1961. - 1990.)

Vegetacijsko razdoblje 2010. godine obilježila je ekstremno velika količina oborine $(2010 .=676,6 \mathrm{~mm} ; 1961 .-1990 .=368 \mathrm{~mm})$. Ističe se mjesec lipanj kada je mjesečna količina oborine za 166\% bila veća u odnosu na višegodišnji prosjek (2010. = $234 \mathrm{~mm}$; 1961. $-1990 .=88 \mathrm{~mm}$ ). Tijekom srpnja i kolovoza javlja se negativna vodna bilanca uz nadprosječno visoke temperature zraka (Tablica 1) radi čega je na a2 tretmanu norma navodnjavanja bila $35 \mathrm{~mm}$, a na a3 tretmanu $105 \mathrm{~mm}$.

Tablica 1. Srednje mjesečne temperature zraka $\left({ }^{\circ} \mathrm{C}\right)$ tijekom razdoblja istraživanja (2010. - 2012.) i višegodišnji prosjek (1961. - 1990.)

Table 1. Average monthly air tempreatures $\left({ }^{\circ} \mathrm{C}\right)$ during period of research and long term average (1961. - 1990.)

\begin{tabular}{ccccccc}
\hline \multirow{2}{*}{ Godina/Year } & \multicolumn{5}{c}{ Mjesec/Month } \\
\cline { 2 - 6 } & IV & V & VI & VII & VIII & IX \\
\hline 2010. & 12,4 & 16,5 & 20,4 & 23,2 & 21,7 & 15,6 \\
2011. & 13,2 & 16,7 & 20,8 & 22,2 & 23,0 & 20,3 \\
2012. & 12,5 & 16,9 & 22,5 & 24,8 & 24,1 & 18,9 \\
1961. -1990. & 11,3 & 16,5 & 19,5 & 21,1 & 20,3 & 16,6 \\
\hline
\end{tabular}


Kao rezultat nadprosječno velike količine oborine razina podzemne vode tijekom mjeseca lipnja bila je $20 \mathrm{~cm}$, dok se tijekom vegetacije kretala od $110 \mathrm{~cm}$ u svibnju do 140 cm u kolovozu (Grafikon 3).

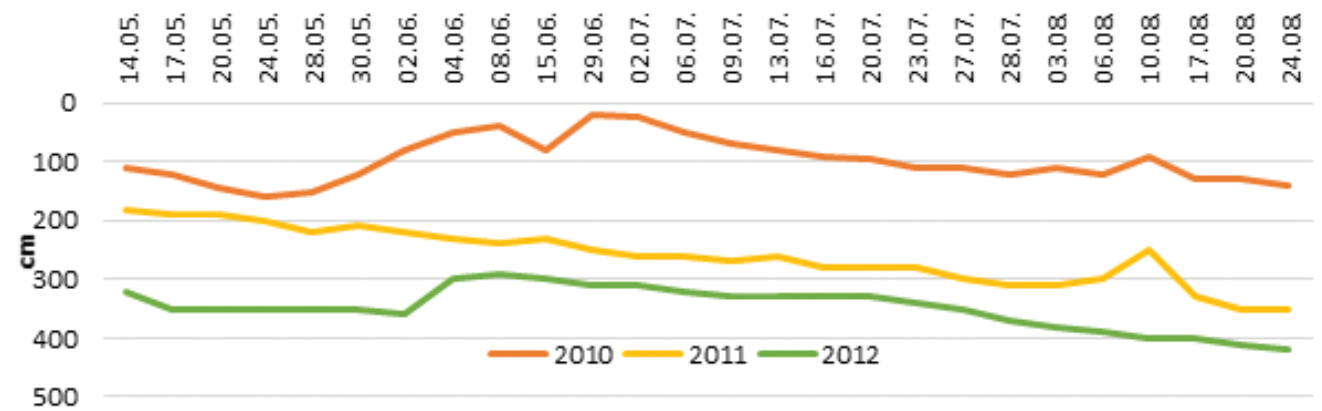

Datum mjerenja/Date of measuring

Grafikon 3. Razine podzemne vode u razdoblju vegetacije (2010. - 2012.)

Figure 3. Groundwater levels during growing seasons (2010 - 2012)

Vegetacijska razdoblja 2011. i 2012. godine bila su sušna i ekstremno topla (Grafikon 2, Tablica 1). Nedostatak oborine tijekom najvažnijih mjeseci za uzgoj jarih kultura bio je popraćen nadprosječno visokim temperaturama zraka. Tijekom sva tri razdoblja vegetacije srednje dnevne temperature zraka bile su više u odnosu na višegodišnji prosjek. Posebno se ističe 2012. godina kada su temperature tijekom srpnja i kolovoza bile za 3,7 i $3,8{ }^{\circ} \mathrm{C}$ iznad višegodišnjeg prosjeka (Tablica 1 ). Razina podzemne vode tijekom vegetacijskog razdoblja 2011. godine bila je vrlo niska, od $180 \mathrm{~cm}$ u svibnju do $350 \mathrm{~cm}$ u kolovozu (Grafikon 3). Još niža razina vode izmjerena je u vegetacijskom razdoblju 2012. godine. Razina vode bila je $320 \mathrm{~cm}$ u svibnju i $420 \mathrm{~cm}$ u kolovozu. Navedeno upućuje na negativne vodne bilance, nedostatak oborine i niže razine podzemne vode, te je stoga tijekom razdoblja vegetacije 2011. godine norma navodnjavanja na a2 tretmanu bila $105 \mathrm{~mm}$, a na a3 $245 \mathrm{~mm}$. Tijekom razdoblja vegetacije 2012. godine norma navodnjavanja na a2 tretmanu bila je $175 \mathrm{~mm}$, a na a3 tretmanu $245 \mathrm{~mm}$.

Utjecaj godine, tretmana navodnjavanja i količine $N$ gnojiva na prinos i komponente prinosa

$\mathrm{U}$ prosjeku po godinama istraživanja prinos zrna kukuruza varirao je u malom rasponu od 8,6 (2010.) do 8,3 t ha-1 (2012.), a razlike između godina opravdane su na razini značajnosti $P<0,05$. Najviši prinos zrna ostvaren je u godini s najvećom količinom oborina (a1), što je posljedica najvećeg ostvarenog prinosa $\left(8,4 \mathrm{t} \mathrm{ha}^{-1}\right) \mathrm{u}$ tretmanu bez navodnjavanja (b1) u odnosu na isti u tretmanu bez navodnjavanja (b1) u godinama a2 (7,3 t ha-1) i a3 $\left(6,7\right.$ t ha $\left.^{-1}\right)$ (Tablica 2$)$. 
Tablica 2. Utjecaj godine, tretmana navodnjavanja i $\mathrm{N}$ gnojidbe na prinos zrna kukuruza

Table 2. Year effect, irrigation treatments and $\mathrm{N}$ fertilizer on maize grain yield

Prinos zrna $\left(t h a^{-1}\right) / g r a i n ~ y i e l d ~\left(t h a^{-1}\right)$

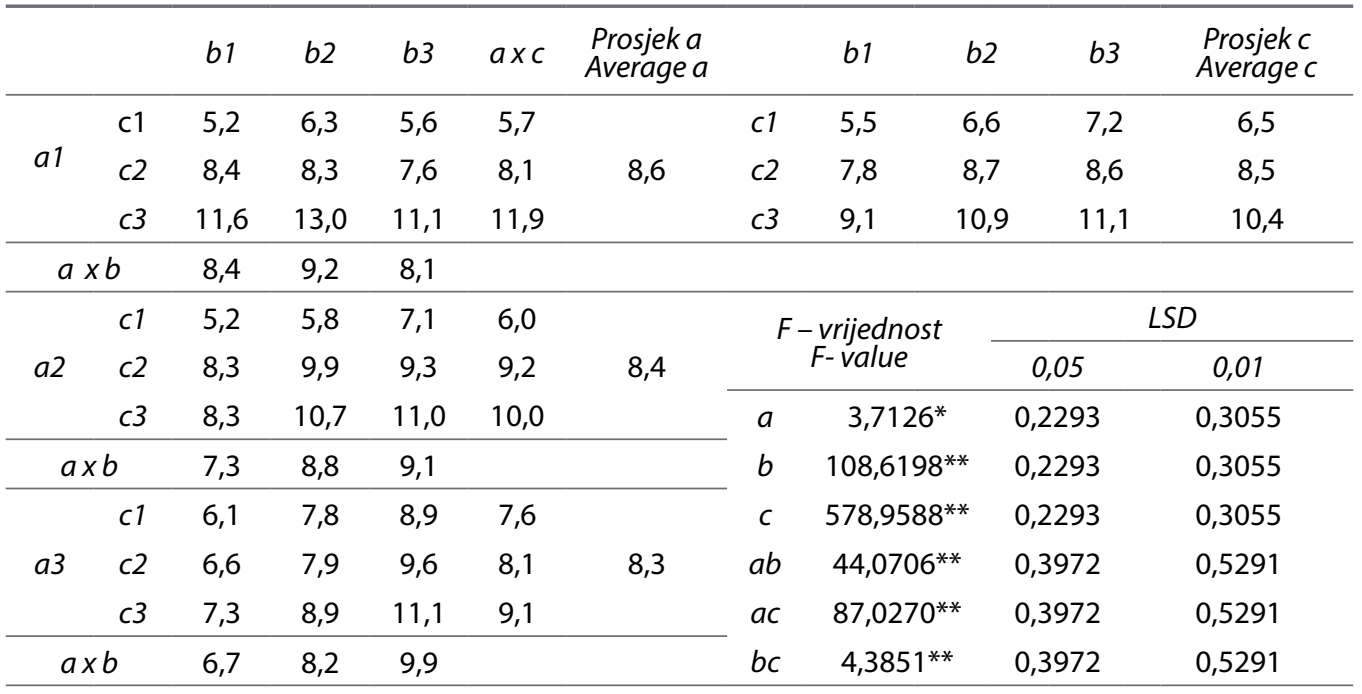

$\begin{array}{cccc}\begin{array}{c}\text { Prosjek } b \\ \text { Average } b\end{array} \quad 7,5 & 8,7 & 9,0\end{array}$

$a=$ godin $; \quad b 1=$ kontrola $; b 2=60-80 \%$ PVK; $b 3=80-100 \%$ PVK; $c 1=$ kontrola $, c 2=100 \mathrm{~kg} \mathrm{~N} \mathrm{ha}^{-1}, c 3=200$

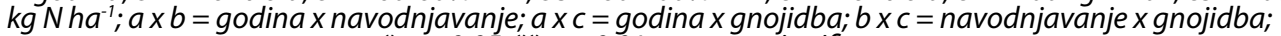
${ }^{*}=p<0,05 ;{ }^{* *}=p<0,01 ;{ }^{\text {n.s. }}=$ non significant

Navodnjavanje je vrlo značajno $(P<0,01)$ povećalo prinos zrna na oba tretmana $u$ odnosu na kontrolni tretman. Prinos zrna 2011. godine bio je za $16 \%$ viši u odnosu na kontrolni tretman, a u 2012. godini za 20\% $(P<0,01)$. Također je utvrđena razlika $(P<0,01)$ između navodnjavanih tretmana pokazuje veću učinkovitost navodnjavanja u sušnim i ekstremno toplim godinama. Na tretmanu navodnjavanja b3 prinos zrna bio je za 3,5\% viši u odnosu na b2 tretman. Prinos zrna kukuruza rastao je $(P<0,01)$ povećanjem dodane količine $\mathrm{N}$ gnojiva (Tablica 2), za 30,8\% viši na c2 tretmanu u odnosu na kontrolni tretman (c1) te za $60 \%$ na c3 tretmanu $(P<0,01)$. Zamijećena je vrlo značajna razlika $(P<0,01)$ u prinosu zrna između gnojidbenih tretmana, na c3 bio je za 22,3\% viši u odnosu na c2 tretman. Rezultati su u skladu s istraživanjima Devi i sur. (2001.), Khaliq i sur., (2009.) te Khazaei i sur. (2010.) koji također navode povećanje prinosa zrna povećanjem količine $\mathrm{N}$ gnojiva. Kako je vidljivo iz tablice 2 , sve interakcije imale su vrlo značajan $(P<0,01)$ utjecaj na prinos zrna. Značajnost interakcije godina $x$ navodnjavanja $(a \times b)$ razlikovala se ovisno o godini istraživanja odnosno vremenskim uvjetima, prvenstveno količini oborine. $U$ ekstremno kišnoj 2010. godini (a1) najviši prinos ostvaren ja na a1b2 interakciji $\left(9,2 \mathrm{t} \mathrm{ha}^{-1}\right)$ dok je daljnjim dodavanjem obroka navodnjavanja na a 1 b3 interakciji prinos zrna smanjen za 3,7\% u odnosu na a1b1 $(\mathrm{P}<0,05)$ te za $13,6 \%$ u odnosu na a1b2 $(\mathrm{P}<0,01)$. Prema Marković i sur. (2015) smanjenje prinosa na b3 tretmanu navodnjavanja rezultat je prekomjerne količine vode u zoni korijenovog sustava koja je uzrokovala nedostatak kisika te gušenje korijena. $U$ 
sušnoj 2011. i vrlo sušnoj 2012. godini prinos zrna na a x b interakciji rastao je povećanjem norme navodnjavanja (Tablica 2 ). U pogledu interakcije godina x gnojidba (a $\mathrm{x}$ c) najviši prinos zrna ostvaren je u godini s najvećom količinom oborine i dodanog $\mathrm{N}$ gnojiva (a1c3 $\left.=11,9 \mathrm{t} \mathrm{ha}^{-1}\right)$. U pogledu interakcije navodnjavanje $x$ gnojidba (b x c) očekivano najviši prinos zrna ostvaren je na b3c3 interakciji $\left(11,1 \mathrm{t} \mathrm{ha}^{-1}\right)$. Hammad $i$ sur. (2012.) također navode značajnost interakcije navodnjavanja x $\mathrm{N}$ gnojidbe za prinos zrna kukuruza. Duljina klipa (DK) kukuruza vrlo je značajno $(P<0,01)$ varirala po godinama istraživanja (Tablica 3$)$.

Tablica 3. Utjecaj godine, tretmana navodnjavanja i N gnojidbe na duljinu klipa

Table 3. Year effect, irrigation treatments and $\mathrm{N}$ fertilizer on cob lenght

\begin{tabular}{|c|c|c|c|c|c|c|c|c|c|c|c|}
\hline \multicolumn{12}{|c|}{ Duljina klipa $(\mathrm{cm}) /$ Cob lenght $(\mathrm{cm})$} \\
\hline & & b1 & $b 2$ & $b 3$ & $a \times c$ & $\begin{array}{l}\text { Prosjek a } \\
\text { Average a }\end{array}$ & & b1 & b2 & b3 & $\begin{array}{l}\text { Prosjek c } \\
\text { Average c }\end{array}$ \\
\hline \multirow{3}{*}{$a 1$} & c1 & 15,9 & 17,1 & 15,1 & 16,1 & & c1 & 18,1 & 20,5 & 19,7 & 18,4 \\
\hline & $c 2$ & 19,7 & 18,9 & 17,7 & 18,8 & 18,6 & c2 & 18,0 & 21,4 & 20,6 & 20,4 \\
\hline & $c 3$ & 21,6 & 20,1 & 21,5 & 21,1 & & c3 & 19,1 & 19,4 & 22,5 & 20,9 \\
\hline \multicolumn{2}{|c|}{$a \times b$} & 19,1 & 18,7 & 18,1 & & & & & & & \\
\hline \multirow{3}{*}{$a 2$} & $c 1$ & 17,1 & 14,9 & 19,7 & 17,2 & \multirow{3}{*}{19,7} & \multirow{2}{*}{\multicolumn{2}{|c|}{$\begin{array}{c}\text { F-vrijednost } \\
\text { F-value }\end{array}$}} & \multicolumn{3}{|c|}{$\angle S D$} \\
\hline & $c 2$ & 21,4 & 22,9 & 20,3 & 21,5 & & & & \multicolumn{2}{|c|}{0,05} & 0,01 \\
\hline & $c 3$ & 19,4 & 18,9 & 22,3 & 20,2 & & a & $15,0240^{* *}$ & \multicolumn{2}{|c|}{1,0371} & 1,3815 \\
\hline \multicolumn{2}{|c|}{$a \times b$} & 19,3 & 18,9 & 20,8 & & & $b$ & $1,4865^{\text {n.s. }}$ & \multicolumn{2}{|c|}{1,0371} & 1,3815 \\
\hline \multirow{3}{*}{$a 3$} & $c 1$ & 21,3 & 22,1 & 22,5 & 22,0 & & c & $13,0038^{* *}$ & \multicolumn{2}{|c|}{1,0371} & 1,3815 \\
\hline & $c 2$ & 20,3 & 22,2 & 20,1 & 20,8 & 21,4 & $a b$ & $2,9123^{*}$ & \multicolumn{2}{|c|}{1,7963} & 2,3928 \\
\hline & $c 3$ & 18,3 & 22,7 & 23,6 & 21,5 & & ac & $7,6584^{* *}$ & \multicolumn{2}{|c|}{1,7963} & 2,3928 \\
\hline \multicolumn{2}{|c|}{$a \times b$} & 19,9 & 22,3 & 22,1 & & & bc & $3,4084^{*}$ & \multicolumn{2}{|c|}{1,7963} & 2,3928 \\
\hline \multicolumn{2}{|c|}{$\begin{array}{l}\text { Prosjek } b \\
\text { Average } b\end{array}$} & 19,4 & 20,0 & 20,3 & & & & & & & \\
\hline \multicolumn{12}{|c|}{ 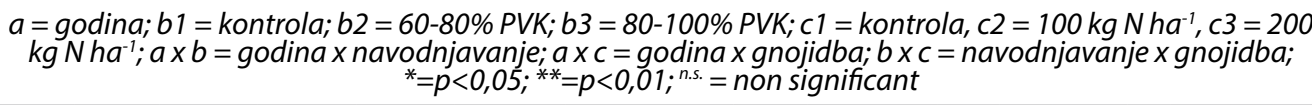 } \\
\hline
\end{tabular}

Najmanja vrijednost zabilježena je u ekstremno kišnoj 2010. godini (a1 =18,6 cm). U sušnoj 2011. (a2) DK bila je za 5,9\% viša u odnosu na a1, te za 15\% u vrlo sušnoj 2012. godini (a3). Nadalje DK kukuruza 2012. godine bila je veća za 8,6\% u odnosu na DK 2011. godine ( $P<0,01)$. Rezultati istraživanja Karasu i sur. (2015.) ukazuju na povećanje DK povećanjem norme navodnjavanja što je rezultat i našeg istraživanja premda bez statističke značajnosti (Tablica 3). DK rasla je povećanjem količine dodanog $\mathrm{N}$ gnojiva $(\mathrm{P}<0,01)$. Na c2 tretmanu DK bila je za 10,9\% veća u odnosu na kontrolni tretman te za 13,6\% na c3 tretmanu u odnosu na kontrolni tretman. DK značajno $(P<0,05)$ je varirala prema $a \times b$ interakciji. Najdulji klip kukuruza zabilježen je na a3b2 i a3b3 $(22,3 \mathrm{~cm}$ i 22,1 cm) interakciji, dakle u vrlo sušnoj godini navodnjavanoj najvećom normom navodnjavanja. Najdulji klip na b x c interakciji izmjeren je na tretmanu s najvećom normom navodnjavanja i dodanom 
količinom $\mathrm{N}$ gnojiva $(22,5 \mathrm{~cm})$. Broj zrna po klipu kukuruza $(\mathrm{BZ} / \mathrm{K})$ razlikovao se po godini istraživanja ( $P<0,01$, Tablica 4).

Tablica 4. Utjecaj godine, tretmana navodnjavanja i N gnojidbe na broj zrna/klipu

Table 4. Year effect, irrigation treatments and $\mathrm{N}$ fertilizer on grain number/cob

\begin{tabular}{|c|c|c|c|c|c|c|c|c|c|c|c|}
\hline \multicolumn{12}{|c|}{ Broj zrna po klipu (n)/Grain number/cob (n) } \\
\hline & & b1 & $b 2$ & $b 3$ & $a \times c$ & $\begin{array}{l}\text { Prosjek a } \\
\text { Average a }\end{array}$ & & b1 & $b 2$ & $b 3$ & $\begin{array}{l}\text { Prosjek c } \\
\text { Average c }\end{array}$ \\
\hline \multirow{3}{*}{$a 1$} & c1 & 448 & 494 & 434 & 459 & & c1 & 506 & 548 & 555 & 536 \\
\hline & $c 2$ & 634 & 561 & 552 & 582 & 566 & $c 2$ & 592 & 617 & 565 & 591 \\
\hline & $c 3$ & 662 & 622 & 684 & 656 & & c3 & 591 & 646 & 717 & 651 \\
\hline \multicolumn{2}{|c|}{$a \times b$} & 581 & 559 & 556 & & & & & & & \\
\hline \multirow{3}{*}{$a 2$} & $c 1$ & 534 & 433 & 538 & 502 & \multirow{3}{*}{585} & \multirow{2}{*}{\multicolumn{2}{|c|}{$\begin{array}{c}\mathrm{F} \text { - vrijednost } \\
\text { F-value }\end{array}$}} & & \multicolumn{2}{|c|}{ LSD } \\
\hline & $c 2$ & 557 & 630 & 610 & 599 & & & & & 0,05 & 0,01 \\
\hline & $c 3$ & 596 & 644 & 725 & 655 & & $a$ & $5,2515^{* *}$ & & 39,5923 & 52,7411 \\
\hline \multicolumn{2}{|c|}{$a \times b$} & 562 & 569 & 625 & & & $b$ & $3,4930^{*}$ & & 39,5923 & 52,7411 \\
\hline \multirow{3}{*}{$a 3$} & $c 1$ & 536 & 717 & 692 & 648 & & $c$ & $170497^{* *}$ & & 39,5923 & 52,7411 \\
\hline & $c 2$ & 585 & 659 & 532 & 592 & 628 & $a b$ & $3,8919^{* *}$ & & 58,5759 & 91,3502 \\
\hline & $c 3$ & 517 & 672 & 742 & 644 & & $a c$ & $5,9293^{* *}$ & & 58,5759 & 91,3502 \\
\hline \multicolumn{2}{|c|}{$a \times b$} & 546 & 683 & 655 & & & $b c$ & $2,8077^{*}$ & & 88,5759 & 91,3502 \\
\hline \multicolumn{2}{|c|}{$\begin{array}{l}\text { Prosjek } b \\
\text { Average } b\end{array}$} & 563 & 604 & 612 & & & & & & & \\
\hline \multicolumn{12}{|c|}{ 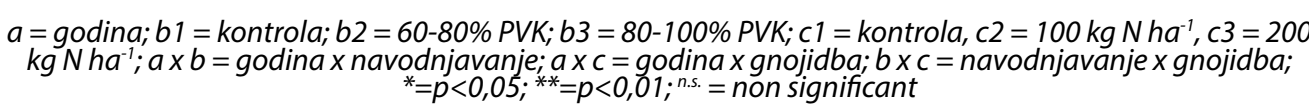 } \\
\hline
\end{tabular}

Najmanja vrijednost zabilježena je u ekstremno kišnoj godini $(a 1=566)$, a najveća vrijednost $u$ vrlo sušnoj godini $(a 3=628)$. BZ/K linearno je rastao povećanjem norme navodnjavanja ( $\mathrm{P}<0,05)$, za 7,3\% (b2 prema b1) te za 8,7\% (b3 prema b1). Povećanjem količine dodanog $\mathrm{N}$ gnojiva rastao je $\mathrm{BZ} / \mathrm{K}(\mathrm{P}<0,01)$ na oba tretmana $\mathrm{u}$ odnosu na kontrolu, za $10,3 \%$ na c2 te za $21,5 \%$ na c3 tretmanu (Tablica 4). Također je zamijećena vrlo značajna razlika između gnojidbenih tretmana. BZ/K na c3 tretmanu bio je za 10,2\% veći u odnosu na c2. Utjecaj a x c interakcije na BZ/K razlikovao se po godini istraživanja. Tijekom ekstremno kišne godine BZ/K smanjivao se povećanjem norme navodnjavanja ( $\mathrm{a} 1 \mathrm{~b} 1=581$, a1b3 = 556) premda ne statistički opravdano dok su za sušnu i vrlo sušnu vegetaciju rezultati suprotni jer je povećanjem norme navodnjavanja zabilježen porast $B Z / K(P<0,01)$. U2011. godini $B Z / K$ na a2b3 tretmanu bio je za $11,2 \%$ veći u odnosu na a2b1. U vrlo sušnoj 2012. godini najveći BZ/K zabilježen je na a3b2 tretmanu (683). Interakcija b x c značajno je utjecala na $B Z / K(P<0,05)$. Najveća vrijednost zabilježena je kod b3c3 tretmana (717). Visina klipa (VK) razlikovala se po godinama istraživanja $(P<0,01$; Tablica 5.). 
Tablica 5. Utjecaj godine, tretmana navodnjavanja i N gnojidbe na visinu klipa

Table 5. Year effect, irrigation treatments and $\mathrm{N}$ fertilizer on cob height

Visina klipa $(\mathrm{cm}) / \mathrm{cob}$ height $(\mathrm{cm})$

\begin{tabular}{|c|c|c|c|c|c|c|c|c|c|c|c|}
\hline & & b1 & $b 2$ & $b 3$ & $a \times c$ & $\begin{array}{l}\text { Prosjek a } \\
\text { Average a }\end{array}$ & & $b 1$ & $b 2$ & $b 3$ & $\begin{array}{l}\text { Prosjek c } \\
\text { Average c }\end{array}$ \\
\hline \multirow{3}{*}{$a 1$} & c1 & 83,2 & 91,7 & 91,3 & 88,7 & \multirow{3}{*}{97,4} & c1 & 108,2 & 113,9 & 119,6 & 113,9 \\
\hline & $c 2$ & 100,8 & 100,0 & 98,0 & 99,6 & & $c 2$ & 116,5 & 125,5 & 126,5 & 122,8 \\
\hline & $c 3$ & 104,3 & 99,5 & 107,5 & 103,8 & & $c 3$ & 120,5 & 122,7 & 131,3 & 124,8 \\
\hline \multicolumn{2}{|c|}{$a \times b$} & 96,1 & 97,1 & 98,9 & & & & & & & \\
\hline \multirow{3}{*}{$a 2$} & c1 & 120,8 & 116,7 & 125,7 & 121,1 & \multirow{3}{*}{133,5} & \multirow{2}{*}{\multicolumn{3}{|c|}{$\begin{array}{c}F-\text { vrijednost } \\
F \text {-value }\end{array}$}} & \multicolumn{2}{|c|}{$L S D$} \\
\hline & $c 2$ & 125,2 & 145,5 & 143,8 & 138,2 & & & & & 0,05 & 0,01 \\
\hline & $c 3$ & 129,8 & 148,0 & 146,2 & 141,3 & & $a$ & 136,41 & $6^{* *}$ & 4,8815 & 6,5027 \\
\hline \multicolumn{2}{|c|}{$a \times b$} & 125,3 & 136,7 & 138,6 & & & $b$ & 9,692 & & 4,8815 & 6,5027 \\
\hline \multirow{3}{*}{$a 3$} & c1 & 120,7 & 133,4 & 141,7 & 132,0 & & c & 11,40 & & 4,8815 & 6,5027 \\
\hline & $c 2$ & 123,5 & 131,0 & 137,7 & 131,7 & 130,7 & $a b$ & 2,025 & & 8,4550 & 11,2630 \\
\hline & $c 3$ & 127,3 & 120,6 & 140,2 & 129,4 & & $a c$ & 4,489 & & 8,4550 & 11,2630 \\
\hline \multicolumn{2}{|c|}{$a \times b$} & 123,8 & 128,3 & 139,9 & & & $b c$ & 0,494 & & 8,4550 & 11,2630 \\
\hline
\end{tabular}

$\begin{array}{cccc}\text { Prosjek b } & 115,1 \quad 120,7 \quad 125,8\end{array}$

$a=$ godin $a ; b 1=$ kontrola $; b 2=60-80 \%$ PVK; $b 3=80-100 \% P V K ; c 1=$ kontrola, $c 2=100 \mathrm{~kg} \mathrm{~N} \mathrm{ha}^{-1}, c 3=200$

$\mathrm{kgNh}{ }^{-1} ; a \times b=$ godina $\times$ navodnjavanje; $a \times c=$ godina $\times$ gnojidba; $b \times c=$ navodnjavanje $\times$ gnojidba; ${ }^{*}=p<0,05 ;{ }^{* *}=p<0,01 ;{ }^{\text {n.s. }}=$ non significant

U sušnoj 2011. godini VK bila je za 37\% veća u odnosu na ekstremno kišnu godinu (a1). Zabilježena je veća ( $P<0,01)$ VK na oba tretmana navodnjavanja, za $5,6 \%$ na b2 te za 10,7\% na b3 u odnosu na kontrolni tretman. Karasu i sur. (2015.) i Bozkurt i sur. (2006.) također navode više biljke na tretmanima s većom normom navodnjavanja. Oba $\mathrm{N}$ tretmana povećala su VK $(P<0,01)$ za $7,8 \%$ na c2 te za $9,6 \%$ na c3 tretmanu u odnosu na kontrolni tretman. Najveće vrijednosti VK u pogledu a x c interakcije zabilježene su kod a2c3 interakcije (141,3 cm). Tijekom ekstremno kišne i sušne godine zabilježen je porast VK povećanjem norme navodnjavanja $(P<0,01)$ dok je u vrlo sušnoj godini VK bila smanjena premda ne statistički opravdano. Analizom korelacijske veze (Tablica 6., $\mathrm{n}=81 ; \mathrm{P}<0,01$ ) dobivena je jaka veza pozitivnog smjera između prinosa i DK $(0,55)$, prinosa i BZ/K $(r=062)$ te srednje jaka veza između prinosa i VK $(r=0,33)$. 
Tablica 6. Analiza korelacijske veze između ispitivanih varijabli $(n=81 ; P<0,01)$

Table 6. Correlation analysis for tested variables $(n=81 ; P<0,01)$

\begin{tabular}{cccc}
\hline $\begin{array}{c}\text { Varijabla } \\
\text { Variable }\end{array}$ & $\begin{array}{c}\text { Visina klipa } \\
\text { Cob height }\end{array}$ & $\begin{array}{c}\text { Duljina klipa } \\
\text { Cob lenght }\end{array}$ & $\begin{array}{c}\text { Broj zrna po klipu } \\
\text { Grain number/cob }\end{array}$ \\
\hline $\begin{array}{c}\text { Visina klipa } \\
\text { Cob height } \\
\text { Duljina klipa } \\
\text { Cob lenght }\end{array}$ & 0,52 & & \\
$\begin{array}{c}\text { Broj zrna po klipu } \\
\text { Grain number/cob }\end{array}$ & 0,46 & 0,81 & \\
Yield & 0,33 & 0,55 & 0,62 \\
\hline
\end{tabular}

Jaka veza pozitivnog smjera je između VK i DK $(r=0,52)$ te BZ/K i VK $(r=0,46)$. Vrlo jaka veza pozitivnog smjera je između BZ/K i DK ( $r=0,81)$. Devi $i$ sur. (2001.), Khaliq $i$ sur. (2009) te Khazaei $i$ sur. (2010.) također navode najjaču korelacijsku vezu između prinosa zrna i $\mathrm{BZ} / \mathrm{K}$.

\section{Zaključak}

Sve veća pozornost daje se učinkovitosti sustava za navodnjavanje zbog količine utrošene vode te ostvarenog prinosa. Prema rezultatima našeg istraživanja učinkovitost sustava za navodnjavanje na prinos zrna i komponente prinosa kukuruza razlikuje se ovisno o vremenskim uvjetima (godini), normi navodnjavanja i količini dodanog $\mathrm{N}$ gnojiva. Norma navodnjavanja trebala bi biti određena prema stvarnim potrebama biljke za vodom u pojedinim razdobljima vegetacije, prvenstveno prema količini oborine, ali i nadprosječno visokim temperaturama zraka koje se javljaju tijekom ljetnih mjeseci što potvrđuju rezultati ovoga istraživanja (godina x navodnjavanje). Nadalje, učinkovitost agrotehničke mjere navodnjavanja trebalo bi sagledati i u odnosu s ostalim agrotehničkim mjerama, prvenstveno $\mathrm{N}$ gnojidbi. U prilog tome govori značajnost interakcije navodnjavanje $\mathrm{x} \mathrm{N}$ gnojidba za prinos zrna i istraživane komponente prinosa jer su u pravilu najveće vrijednosti izmjerene na tretmanima s najvećom normom navodnjavanja i količinom $\mathrm{N}$ gnojiva.

\section{Literatura}

Bozkurt, Y., Yazar, A., Gencel, B., Sezen, M.S. (2006). Optimum lateral spacing for drip-irrigated corn in the Mediterranean Region of Turkey. Agricultural Water Management, 85, 113-120.

Carpici, E.B. (2009). Evaluation of the effects of plant densities and nitrogen rates on stress physiology traits in silage corn (Zea mays L.) production. PhD thesis, Field Crops, Graduate School of Natural and Applied Sciences. Uludag University, Bursa, Turkey

D'Andrea, K.E., Otegui, M.E., Cirilo, A.G. (2008). Kernel number determination differs among maize hybrids in response to nitrogen. Field Crops Research, 105, 228-239.

Devi, I.S., Muhammad, S., Mohammad, S. (2001). Character association and path coefficient analysis of grain yield and yield components in double cross of maize (Zea mays L.). Crop Research Hisar, 21 (3), 335-359.

Državni zavod za statistiku, DZS (2016). Biljna proizvodnja.

http://www.dzs.hr/Hrv_Eng/publication/2017/01-01-14_01_2017.htm (10.06.2017)

Ertek, A., Kara, B. (2013).Yield and quality of sweet corn under deficit irrigation. Agricultural Water Management, $129,138-144$.

FAO, Food and Agriculture Organization of the United Nations (1985). Water Quality for Agriculture. http://www. fao.org/docrep/003/T0234E/T0234E00.htm (10.06. 2017)

Hammad, H.M., Ahmad, A., Abbas, F., Farhad, W. (2012). Optimizing water and nitrogen use for maize production under semiarid conditions. Turkish Jurnal of Agriculture and Forestry, 36, 519-532.

Gavloski, J. E., Whitfield, G. H., Ellis, C.R. (1992). Effect of restricted watering on sap flow and growth in corn (Zea 
mays L.). Canadian Journal of Plant Science, 72, 361-368.

Golbashy, M., Ebrahimi, M., Khorasani, S.K., Choukan, R. (2010). Evaluation of drought tolerance of some corn (Zea mays L.) hybrids in Iran. African Journal of Agricultural Research, 5, 2714-2719.

Jaleel, C.A., Manivannan, P., Wahid, A., Farooq, M., Al-Juburi, H.J., Somasundaram, R., Panneerselvam, R. (2009). Drought stress in plants: A review on morphological characteristics and pigments composition. International Journal of Agriculture \& Biology, 11, 100-105.

Karasu, A., Kuşcu, H., Öz, M., Bayram, G. (2015). The Effect of Different Irrigation Water Levels on Grain Yield, Yield Components and Some Quality Parameters of Silage Maize (Zea mays indentata Sturt.) in Marmara Region of Turkey. Notulae Botanicae Horti Agrobotanici Cluj-Napoca, 43 (1), 138-145.

Khaliq, T., Ahmad, A.H., Ali, M.A. (2009). Maize hybrids response to nitrogen rates at multiple locations in semiarid environment. Pakistan Journal of Botany, 41 (1), 207-224.

Khazaei, F., Agha Alikhani, M., Yari, L., Khandan, A. (2010). Study the correlation, regression and path coefficient analysis in sweet corn (zea mays var. saccharata) under different levels of plant density and nitrogen rate. ARPN Journal of Agricultural and Biological Science, 5 (6), 14-19.

Kuscu, H. (2010). Effects of deficit irrigation on yield and yield components of maize grown under Bursa conditions. $\mathrm{PhD}$ thesis, Irrigation and Agricultural Structures, Graduate School of Natural and Applied Sciences, Uludag University, Bursa, Turkey.

Kuscu, H., Demir, A.O. (2013). Yield and water use efficiency of maize under deficit irrigation regimes in a subhumid climate. Philippine Agricultural Scientist , 96 (1), 32-41.

$\mathrm{Li}$, X., Wang, Y. (2011). Relationship between maize yield and ear characters under supplementary irrigation with catchment rainfall. International Conference on Agricultural and Biosystems Engineering Advances in Biomedical Engineering, 1-2, $324-327$

Marković, M. (2013). Učinkovitost navodnjavanja i gnojidbe dušikom na prinos i kvalitetu zrna hibrida kukuruza (Zea mays L.). Doktorska disertacija, Poljoprivredni fakultet u Osijeku.

Marković, M., 'Tadić V., Josipović, M., Zebec, V., Filipović, V. (2015). Efficiency of maize irrigation scheduling in climate variability and extreme weather events in eastern Croatia. Journal of Water and Climate Change, 6 (3), 586 - 595.

Payero, J.O., Melvin, S.R., Irmak, S., Tarkalson, D. (2006). Yield response of corn to deficit irrigation in a semiarid climate. Agricultural Water Management, 84, 101-112.

Soler, C.M.T., Hoogenboom, G., Sentelhas, P.C., Duarte, A.P. (2007). Impact of water stress on maize grown off -season in a subtropical environment. J Agron Crop Sci, 193, 247-261.

Traore, S.B., Carlson, R.E., Pilcher, C.D., Rice, M.E. (2000). Bt and Non-Bt maize growth and development as affected by temperature and drought stress. Agronomy Journal, 92, 1027-1035.

\section{Effciency of irriagtion system of maize (Zea mays L.) in different weather conditions, irrigation treatments and $\mathbf{N}$ fertilizers}

\footnotetext{
Abstract

Field trials (2010 - 2012) were conducted to study the influence of the year $(a 1=2010 ; a 2=2011 ; a 3=$ 2012); irrigation treatment ( $b 1=$ control; $b 2=60$ to $80 \%$ field water capacity (FWC), b3 $=80$ to $100 \%$ FWC) and $N$ fertilizers (c1 = control; $\left.c 2=100 \mathrm{~kg} \mathrm{~N} \mathrm{ha}^{-1} ; \mathrm{c3}=200 \mathrm{~kg} \mathrm{~N} \mathrm{ha}^{-1}\right)$ on grain yield $(\mathrm{GY})$ and following yield components: cob length (CL), cob height (CH), grain number/cob (GN/C) and correlation connections between the tested variables. $G Y\left(P<0,05 ;\right.$ a1: 8.6 to a3: $8.3 \mathrm{tha}^{-1}, \mathrm{CH}(P<0.01 ;$ a 1: 97.4 to a2: $133.5 \mathrm{~cm})$, $C L(P<0.01 ; a 1: 18.6$ to a3: $21.4 \mathrm{~cm})$ and $G N / C$ (a1: 566 to a3: 628) were year depenedent. Irrigation water increased $(P<0.01) \mathrm{GY}\left(\mathrm{b} 1: \mathrm{7.5}\right.$ to b3: $\left.9 \mathrm{t} \mathrm{ha}^{-1}\right), \mathrm{CH}(\mathrm{a} 1: 115.1$ to a3: $125.8 \mathrm{~cm})$ and GN/C (b1: 536 to b3: 612). The larger amount of $N$ fertilizers increased $G Y\left(P<0.01 ; c 1: 6.5\right.$ to $c 3: 10.3$ tha $\left.{ }^{-1}\right), C L(c 1: 18.4$ to $c 3: 20.9 \mathrm{~cm})$, GN/C (c1: 536 to $c 3: 651)$ and CH (c1: 113.5 to $c 3: 124.8 \mathrm{~cm}$ ). Strong postivie correlation is between GY and $C L(r=0.55)$ and $G Y$ and $G N / C(r=0.62)$.

Key words: year, irrigation, $N$ fertilizer, maize, yield, yield components
} 